Original Research Paper

\title{
New Projects Sharing Ratios under Musharakah Financing: A Repeated Game Theoretical Approach Using an Output versus a Proposed Effort Based Contract
}

\author{
Adil Elfakir and Mohamed Tkiouat \\ Laboratory of Research in Applied Mathematics, IFE-Lab, \\ Ecole Mohammadia d'Ingenieurs, Mohammed V University, Rabat, Morocco
}

\section{Article history}

Received: 20-08-2015

Revised: 05-09-2015

Accepted: 29-09-2015

Corresponding Author: Adil Elfakir

Laboratory of Research in Appied Mathematics, IFE-Lab, Ecole Mohammadia

d'Ingenieurs, Mohammed V

University, Rabat, Morocco

Email: aelfakir@hotmail.com

\begin{abstract}
In this research, we provide a game theoretical approach of new projects financed under musharakah contracts using two types of contracts. The first type is effort based. It compensates the agent for the effort provided regardless of market conditions. The other type of contract is output based where the agent compensation is based solely on output realized. Our intuition is, on one hand, that an agent acceptance of an effort based contract signals a higher ability and therefore merits a higher compensation. On the other hand, an agent opting for an output based signals a reliance on market condition and therefore a lower effort ability meriting lower compensation. We found evidence that an effort based contract offer better compensation to the agent in the form of lower sharing ratio to the financier. This result has two important Islamic implications. First it emphasizes the sentiment of altruism which the financier shows by taking a smaller sharing ratio. Second it emphasizes the sentiment of positive reciprocity which the agent exhibits by providing high effort. Another finding is that an effort based contract offers more span of negotiation than an output based contract. This is an important Islamic concept as the agent has fewer restrictions in terms of negotiations. This paper tackle two problems of information assymetries. Namely it tackles adverse selection and moral hazards.
\end{abstract}

Keywords: Musharakah, Effort Based Contracts, Output Based Contracts, Sharing Ratio, Moral Hazard, Adverse Selection

\section{Introduction}

Musharakah represents a form of partnership whereby two or more participants provide capital and/or labor to form a business. An exact profit sharing ratio has to be agreed upon in advance (Rammal, 2004). Losses on the other hand cannot exceed each partners contribution (Usmani, 2002). Management of the business can be undertaken by one or several partners. However partners might designate one partner to run the business (Warde, 2010). The non-management parties (Silent partners) are entitled to a share of profits not allowed to exceed their share of investment (The Concept of Musharakah' Presented at AlHuda CIBE Workshop at NIBAF-State Bank of Pakistan Islamabad by Dr. Muhammad Zubair Usmani, Sharia advisor, Muslim Commercial Bank Ltd, Jamia Darul Uloom Karachi). The profit sharing ratio cannot be based on a lump-sum or a percentage of capital. This to avoid a promise of a guaranteed profit.

Partners can decide to retain profits in the venture for further investment. In terms of liability, the participants in a musharakah contract normally have unlimited liabilities.

The termination of musharakah can occur when (Usmani, 2002):

- The partnership was limited to a given time frame

- The purpose of the partnership has been achieved

- The continuity of the project is compromised by the withdrawal of one or several partners

- Any of the partners die before the end of the agreement

- In the case of premature termination, the business shall be liquidated and the settlement distributed pro-rata 
There exist some radical differences between conventional profit sharing and Islamic musharakah:

- Lamic jurisprudence (Shari'ah). For example musharakah is interest-free financing and prohibits the financing of illicit projects (gambling, casinos, wine and pornography). This restriction limits the number of investment opportunities of Islamic musharakah compared to their conventional counterparts

- Islamic musharakah participants do not receive fixed compensation like their conventional counterparts. The former may lose due to the profit and loss sharing principle

- In addition, because the entrepreneur is most often not the provider of funds he may behave in opportunistic ways the maximum loss a participant in musharakh can incure is their personal contribution in the project. In conventional profit and loss sharing contract, the agent, not the financier might lose more than his contribution. This is due to the fact that under a conventional system, the financier might seek warranities against losses, while this is not permissible in Islamic musharakah

Section 2 starts with a literature review of asymmetric information in a financier-entrepreneur environment. Section 3 revisits the original model and presents our proposed model to reduce moral hazards. Section 4 presents the methodology. Section 5 represents the results. Section 6 discusses the outcomes and finally section 7 concludes with a summary and possible extensions.

\section{Literature Review}

In general a financier-entrepreneur relationship suffers from asymmetric information where the entrepreneur has an informational advantage about the project compared to the financier.

The use of dissipative signals by the financier is important to overcome this problem. Collateral, as an example, can be used by efficient agents to signal their type. This is consistent with some research that claims that banks can use collateral in debt contracts to overcome information asymmetries, in particular arising from ex-ante adverse selection (Berger et al., 2011).

Consistent with this findings (Karim, 2002) argues that the agent's sub-mission of a warranty can resolve the adverse selection problem in a profit and prohibited in musharakah under the Islamic jurisprudence (Shari'ah law). Yet, if there is proof of negligence or breach of the contract terms the recourse to a warranty is permissible (Adoption of AAOIFI Shariah Standard No. 12 pertaining to
Sharika (Musharaka) and Modern Corporations. Clause 3/1/4/1: "All partners of Sharika shall be deemed to be trustees in respect of Sharika assets; however, as trustees they shall be jointly and severally liable for misconduct, negligence or breach of contract.").

Agents can signal their type by signing for low job protection. This is similar to a high pledged collateral. i.e., a confident manager will demand a high reward in case of success but also signs for a low job protection in case of failure. This is consistent with previous research as in (Subramanian et al., 2002). Low job protection, however, can be seen as unfair to the entrepreneur since failure of the project can be due to factors beyond the entrepreneur's control. Demanding security by the financier, in the form of low job protection, can be seen as making the entrepreneur lose more than his contribution. This, however, contradicts the musharakah principle which calls for a fair sharing of profits and losses as mentioned earlier by (Usmani, 2002).

Information sharing can be used to reduce information asymmetry. In fact, credit bureaus have been shown to increase efforts from borrowers (Padilla and Pagano, 1997). Information sharing is useful if borrower mobility is higher (Pagaon and Jappelli, 1993) and if asymmetric information problems are more important (Brown and Zehnder, 2010). Empirical research has shown that, information sharing is correlated with higher access to credit (Pagaon and Jappelli, 1993), especially in developing countries with inefficient creditor rights (Djankov et al., 2007), but lower lending to low-quality borrowers (Hertzberg et al., 2011).

However, it is shown that due to information sharing, benefits from banking relationships are reduced resulting in a weaker banking competition (Gehrig and Stenbacka, 2007).

One of the main problems with Musharakah is misreporting. This occures when the agent reports losses while the project is making profits. Al-Suwailem (2006) argues that, there should be a higher due diligence from the part of the Islamic institutions as compared to conventional banks to overcome the misreporting issue. In our paper, the due deligence can only happen in an effort based contract but not in an output based contract.

One argument suggests that the agency problem is based on an unfair distribution of returns if the project fails (Shaikh, 2011). Taking into consideration the risks related to a project, the financial institution may demand a higher sharing ratio. This, according to Shaikh (2011) however may result in less motivation of the entrepreneur and therefore a lower project returns. In our paper, we have developed two contract schemes (effort based Vs output based) which give the agent the choice between a high or low ratio. This choice, in our opinion signals which type of agents the financier is dealing with. 
Also, it is proposed that the entrepreneur's participation in the capital can reduce information asymmetries in a profit and loss contract (Karim, 2002). Consistent with this finding, we have allowed for the possibility that the agent can participate in the capital of the project.

To induce the entrepreneur to exert high effort and therefore reduce moral hazard, a research suggested a minimum capital contribution by the entrepreneur given a minimum profit sharing ratio (Nabi, 2013). In our model we do not impose a minimum capital contribution by the agent. This is intuitive as the agent might not have the required fund. We proceeded differently by taking the available contribution of the agent and then propose the optimum sharing ratios under each contract.

In dealing with moral hazard, one research suggested that it can be solved under mudharabah (An Islamic term for a form of business in which the financier is the sole provider of capital (Rab'al Mal) and the entrepreneur is the provider of work and management (Mudarib)) but cannot be solved under musharakah (Yousfi, 2013). This can be criticized in a sense that under mudharabah the financier provides the whole capital and therefore assumes all monetary risks. On the other hand under musharakah the capital is shared and intuitively the risk of losing capital is shared. This is, also, inconsistent with our findings and the findings of Nabi (2013) which proposes that moral hazards can be solved subject to a contribution from the entrepreneur. i.e., moral hazard is more likely to be solved under a musharakah contract than under a mudharabah contract. This is also inconsistent with the findings of Innes (1990) who argues that sharing contract is not feasible in case of total external financing of the project.

Another research, proposed the usage of two profit sharing ratios instead of one to reflect the effort of the entrepreneur compared to the financier (Maheran, 2010). The model proposed, however, suffers from the non treatment of asymmetric information.

In a previous paper (ELFakir and Tkiouat, 2015) of ours we have proposed an incentive scheme to deal with moral hazards. This scheme allows for higher social value and more freedom to the agent in terms of negotiating the profit sharing ratio. However the model contrary to the current one, does not provide for two contracts type and does not extent to a two period framework.

\section{The Model}

Our Model involves a financier and an agent who are willing to engage in a musharakah contract costing $F$ in the first period and rolling over the investment into another period. The financier is endowed with an initial wealth $\mathrm{K}>\mathrm{F}$ while the agent is endowed with an intial wealth $\mathrm{f}_{0}$ and would like complementary financing $X_{1} \% F$. The project output $I I\left(E_{i}, M_{i}\right)$ is a function of the agent's effort $\left(E_{i}\right)$ and market conditions $\left(M_{i}\right)$ Where the subscript $i \in\{h, 1\}$ stand for higher and lower values of Effort and market conditions. The project is estimated to yield an output of $I I\left(E_{i}, M_{i}\right)$ and 0 with a probability $P\left(E_{i}, M_{i}\right)$ and 1$P\left(E_{i}, M_{i}\right)$ respectively such that:

$$
\Pi_{(E h, M h)}>\Pi_{(E l, M h)}>\mathrm{F}>\Pi_{(E h, M l)}=\Pi_{(E l, M l)}=0
$$

For simplicity we can put the following notations:

$$
\begin{aligned}
& P_{(E h, M h)} I I_{(E h, M h)}=\overline{\overline{I I}} \quad P_{(E l, M h)} I I_{(E l, M h)}=\overline{I I} \\
& P_{(E h, M l)} I I_{(E h, M l)}=0 \quad P_{(E l, M l)} I I_{(E l, M l)}=0
\end{aligned}
$$

We notice that under low economic conditions it is assumed a null output results even under high effort.

The agent has a cost $C_{h}\left(C_{l}\right)$ for undertaking a high (low effort) respectively. The financier on the other hand has opportunity costs $p_{1}$ and $p_{2}$ in period 1 and period 2 respectively.

Assumption 1 if the agent has chosen not to undertake the project he will get a wage $W_{h}\left(W_{l}\right)$ if he exerts a high (low) effort. We assume that the marginal wage exceed the marginal cost from exerting high effort.

The agent and the financier have common beliefs about current and expected market condition. We will focus on a very specific case: That of new projects which are usually characterized by difficulties in their first stage followed by prosperity in the later stages. The agent has two contract choices offered by the financier: An output based contract referred to as Contractl and an effort based contract referred to as contract 2 .

\section{Contract 1: Output Only}

This type compensates the agent with respect to output produced. We believe that this type of contract leaves much room for random shocks (market conditions) to shape up the compensation of the game participants. From our point of view a reliance on this type of contract signals a weak effort position of the agent and therefore merits lower compensation. In our musharakah context a compensation to the agent is based on a higher predetermined profit sharing ratio $\alpha_{h}$ retained by the agent. Therefore and given a specified market condition in each period, the financier set up its profit sharing ratio low enough to at least achieve its market required rate of return $p$.

In this case an expected output of $\Pi\left(E_{l}, M_{l}\right)=P\left(E_{h}\right.$, $\left.M_{l}\right) \Pi\left(E_{h}, M_{l}\right)=0$ whether the agent performs a high or low effort. In case the agent has performed a high 
effort, the agent is assumed to have developed a productive ability $A$. As we know from contract (1) the output here is used as a signal of the agent weak effort. Therefore, the financier charge a higher sharing ratio if the contract is to be rolled over for another period.

Since there is a loss in first period the sharing ratio is simply $\beta$. Since there is an expected gain $\Pi\left(E_{h}, M_{h}\right)_{i}$ in the second period even under low effort, the financier expects that the agent did not develop a productive ability. The profit sharing ratio $\alpha_{h}$ is determined as:

$$
\alpha_{h 2} \frac{F\left[\beta_{1}\left(1+p_{1}\right)\left(1+\delta\left(1+p_{2}\right)\right)+\delta\left(1+p_{2}\right)\right]}{\delta I \bar{I}}
$$

Where:

$$
\begin{array}{ll}
\delta & =\text { The discount factor of the financier } \\
A & =\text { The expected productive ability } \\
\beta_{2} / E_{h}, M_{l}= & \text { The capital contribution of the financier in } \\
& \text { period } 2 \text { given high effort and low market } \\
& \text { conditions in period } 1
\end{array}
$$

\section{Contract 2: Effort Only}

This type compensates the agent with respect to effort produced. This form however assumes that the agent believes in the objectivity of effort assessment and that incentives in case of positive assessments will be rewarded. We believe that this type of contract does not leave much room for random shocks (market conditions) to shape up the compensation of the game participants. From our point of view the choice of this type of contract signals a high confidence of the agent in his abilities and therefore merits higher compensation. In our musharakah context a compensation to the agent is based on a lower predetermined profit sharing ratio $\alpha_{l}$ retained by the financier. Therefore and given a specified market condition in each period, the financier set up its profit sharing ratio low enough to at least achieve its market required rate of return $\rho$.

In this case an expected output of $\Pi\left(E_{l}, M_{l}\right)=\Pi\left(E_{l}\right.$, $\left.M_{l}\right)=0$ is realized in the first period. Because the contract is effort based, the financier can tell, thanks to due diligence, whether the agent has performed a high or low effort. This results in no renewal of the contract in the second period in case the agent excreted a low effort. In case the agent has performed a high effort the contract is renewed with the assumption that the agent will continue with high effort and applying his acquired productivity $A$.

Since there is a loss in first period The sharing ratio is simply $\beta$. Since there is an expected gain $\Pi\left(E_{h}, M_{h}\right) i \mathrm{~F}$ in the second period under high effort, the profit sharing ratio $\alpha_{12}$ is determined as: $\alpha_{h 2} \frac{F\left[\beta_{1}\left(1+p_{1}\right)\left(1+\delta\left(1+p_{2}\right)\right)+\delta\left(1+p_{2}\right)\right]}{\delta \overline{\overline{I I}}}$

From (1) and (2) we can infer that $\alpha_{l 2}<\alpha_{h 2}$ since $A \overline{I I}>\overline{I I}$. This implies that the agent is offered a higher incentive if he opts for an effort based contract.

\section{A Decision Tree Representation of the Model}

The following diagram represents our model under the two state of nature discussed above.

The financier starts by offring contract or contract 2 . The agent then decides to excert a high $E_{h}$ or low effort $E_{l}$. In the second period, the decision of the financier depends on the type of the contract and the outcome of period 1 . In contract 1 the financier lacks effort assessement and therfore has no choice but to continue the contract. Given the risk embeded in this contract the financier has predetermined in advance a high sharing ration $\alpha_{h 2}$.

In contract 2 (effort based), the financier can judge whether the result was the fruit of high or low effort. A proof of negligence in the form of low effort result in the termination of the contract by the financier without proceeding to the next stage. Because, the agent has opted for this contract, he shows great confidence in his abilities meriting high compensation. The ratio $\alpha_{l 2}$ is predetermined in advance.

The agent then decides to opt for high $E_{h}$ or low effort $E_{l}$. The outcomes of the combination of the strategies of each participant is depicted in the last coloumn as output.

\section{Methodology}

Now that we have determined the minimum sharing ratios under each contract, we can proceed using a game theoretical framework.

The first step is to determine the payment to each participant under each contract given a first stage low market conditions. The second step is to determine the refinancing decisions of each contract. The third step is to look for an optimal choice for both the financier and the agent.

\section{Step 1: Participant's Payoff in Period 1}

Table 1 provide the payoff to the financier and to the entrepreneur in period 1 under each market condition $\mathrm{M}_{\mathrm{i}}$

To illustrate, the financier has the choice to offer to the agent contract 1 or contract 2 . The agent then accepts one of the contracts or reject them to get his opportunity cost.

$\left(W_{h}-C_{h}\right.$ or $\left.W_{l}-C_{l}\right)$ given his high and low effort respectively. The agent then depending on his contract 
options has two strategies under each contract: Exert a high or low effort.

Participants Payoff in Period 1 if Market Conditions are Low (i.e., $M_{i}=M_{l}$ )

Since the output is null under low market conditions regardless of the effort level, the payoff to the financier and the agent respectively are:

$$
\begin{aligned}
& \left.\left[U F\left(C_{i}, E_{i}\right)\right] / M_{l}\right]=\left(k-\beta_{1} F\right)\left(1+\rho_{1}\right) \\
& \left.\left[U E\left(E_{i}, C_{i}\right)\right] / M_{l}\right]=-\left(1-\beta_{1}\right) F-C_{h}
\end{aligned}
$$

\section{Step 2: Refinancing Decisions}

Table 2, extends Table 1 to two periods. We provide the payoffs to the financier and the entrepreneur under each contract $\mathrm{C}_{\mathrm{i}}$ and under each market condition $\mathrm{M}_{\mathrm{i}}$.

To illustrate, we decide on the refinancing decision of each contract on its own. To do so, in period 2, we apply the reciprocity principle where low effort from the agent are punished by the application of a higher profit sharing ratio (given to the financier) or no renewal of the contract. On the other hand a high effort is rewarded by a lower sharing ratio (given to the financier) with the possibility of contract renewal. The following two Tables summarize the refinancing decision under each contract.

The first column represents the state of the world which includes the expected state of nature and the effort level. The second column represents our assumed decision of refinancing. The third column represents the financier share in case of refinancing. The last column represents the amount decided to be invested in the opportunity cost.

\section{Step 3: Best Contract to be Offered by the Financier}

In this case we need to proceed via backward induction under each state of market in both periods by referring to Fig. 1 .

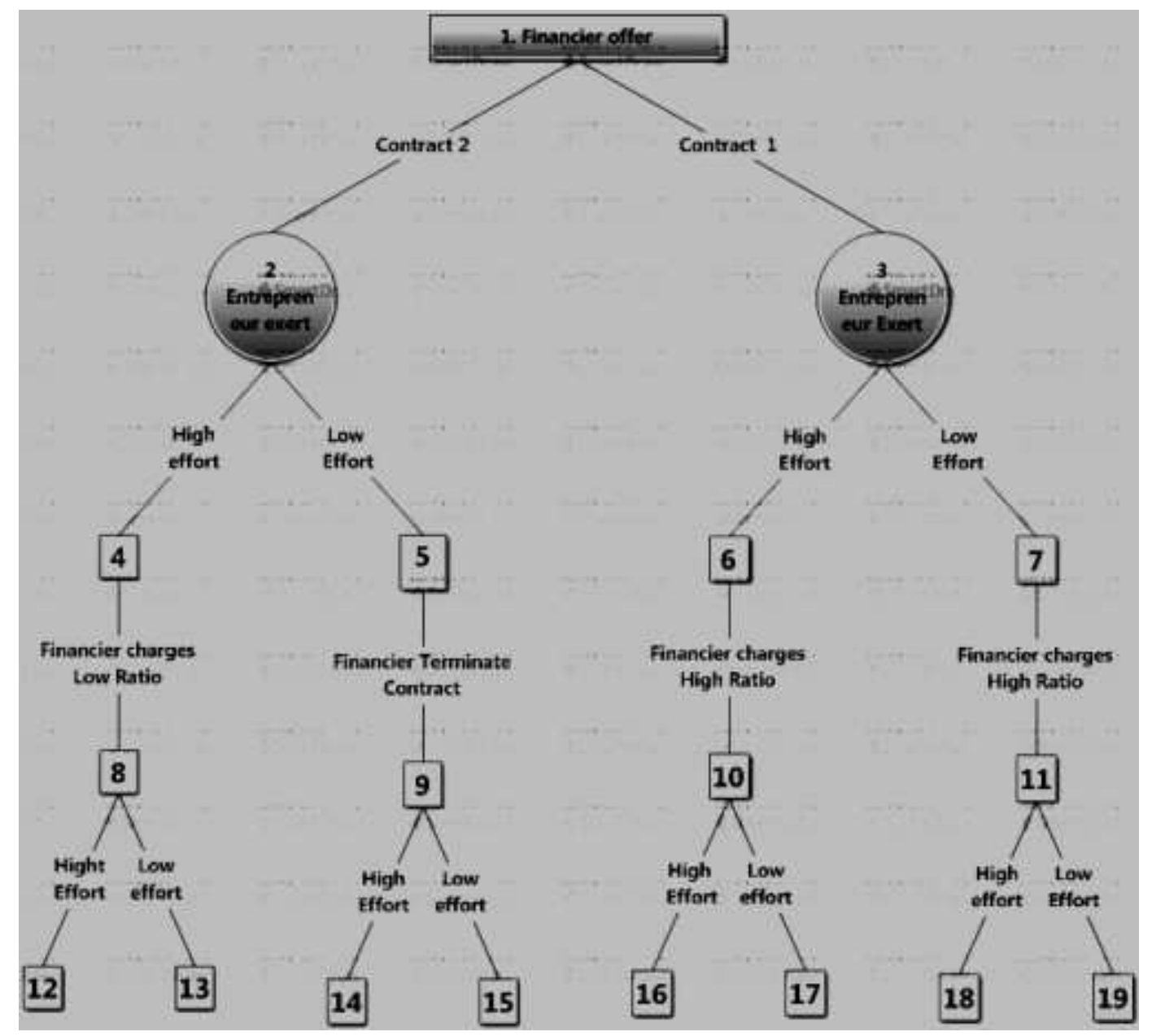

Fig. 1. The Model under a first stage low market followed by a second stage high market 
Table 1. Payoff to financier and agent give each participant's strategy and market condition $M_{i}$ in period 1

\begin{tabular}{|c|c|c|c|}
\hline \multirow[b]{2}{*}{ Financier } & \multirow[b]{2}{*}{ Strategy } & \multicolumn{2}{|l|}{ Entrepreneur } \\
\hline & & $E_{h}=M_{i}$ & $E_{l}=M_{i}$ \\
\hline & $\begin{array}{l}\mathrm{C} 1=M_{i} \\
\mathrm{C} 2=M_{i} \\
\text { No contract }\end{array}$ & $\begin{array}{l}{\left[U_{F}\left(C 1 ; E_{h}\right) ; U_{E}\left(E_{h} ; C 1\right)\right] / M_{i}} \\
{\left[U_{F}(C 2 ; H) ; U_{E}(H ; C 2)\right] / M_{i}} \\
(1+p) X \% F ; C_{h}\end{array}$ & $\begin{array}{l}{\left[U_{F}\left(C 1 ; E_{l}\right) ; \mathrm{U}_{\mathrm{E}}\left(E_{l} ; C 1\right)\right] / M_{i}} \\
{\left[U_{F}(C 2 ; L) ; \mathrm{U}_{\mathrm{E}}(L ; C 2)\right] / M_{i}} \\
(1+p) \mathrm{X} \% F ; C_{l}\end{array}$ \\
\hline
\end{tabular}

Table 2. Refinancing decisions for each contract

\begin{tabular}{llll}
\hline State of the world & Decision on refinancing & New Financier share in project & Investment in opportunity cost \\
\hline$M_{l} ; E_{h} ; \mathrm{C} 2$ & Yes & $\beta_{2}=E_{h} ; M_{l}=1$ & $\left(K-F\left(1+\beta_{1}\right)\right)\left(1+\mathrm{p}_{1}\right)$ \\
$M_{i} ; E_{l} ; \mathrm{C} 2$ & No & $\beta_{2}=E_{l} ; M_{l}=0$ & $\left(K-\beta_{1} F\right)(1+p 1)$ \\
$M_{l} ; E h ; \mathrm{C} 1$ & Yes & $\beta_{2}=E_{h} ; M_{l}=1$ & $\left(K-\mathrm{F}\left(1+\beta_{1}\right)\right)\left(1+p_{1}\right)$ \\
$M_{l} ; E_{i} ; \mathrm{C} 1$ & No & $\beta_{2}=E_{l} ; M_{l}=0$ & $\left(K-\beta_{1} F\right)(1+p 1)$ \\
\hline
\end{tabular}

\section{Results}

We start by comparing the end nodes, in the above tree, which represent the final outcomes to the agent. The nodes to be compared in pairs are: (12 and 13) (14 and 15) (16 and 17) (18 and 19):

Payoff in node $12=-\left(1-\beta_{1}\right) F-C_{h}+d\left[\left(1-\alpha_{l 2}\right) A \overline{\overline{I I}}-C_{h}\right]$ Payoff in node $13=-\left(1-\beta_{1}\right) F-C_{h}+d\left[\left(1-\alpha_{l 2}\right) A \overline{I I}-C_{l}\right]$

For the agent to exert a high effort (i.e., choose node 12) we must have: Payoff in node $12>$ Payoff in node 13. i.e., we must have:

$$
d\left[\left(1-\alpha_{l 2}\right) A \overline{\overline{I I}}-C_{h}\right]>d\left[\left(1-\alpha_{l 2}\right) A \overline{\overline{I I}}-C_{l}\right]
$$

So to exert a high level we must have:

$$
\alpha_{l 2}<1-\frac{C_{h}-C_{l}}{A(\overline{\overline{I I}}-\overline{I I})}
$$

Now we compare payoffs in node 14 and 15 :

Payoff in node $14=-\left(1-\beta_{1}\right) F-C_{l}+d\left[W_{h}-C_{h}\right]$ Payoff in node $15=-\left(1-\beta_{1}\right) F-C_{l}+d\left[W_{l}-C_{l}\right]$ From assumption 1 we have $W_{h}-C_{h}>W_{l}-C_{l}$

So Payoff in node 14> Payoff in node 15 .

Now we compare the payoffs to the agent under (16) and (17):

Payoff in node $16=-\left(1-\beta_{1}\right) F-C_{h}+d\left[\left(1-\alpha_{h 2}\right) A_{c 1} A \overline{\overline{I I}}-C_{h}\right.$ Payoff in node $17=-\left(1-\beta_{1}\right) F-C_{h}+d\left[\left(1-\alpha_{h 2}\right) A \overline{I I}-C_{l}\right.$

For the agent to exert a high effort (i.e., choose node 16) we must have: Payoff in node 16>Payoff in node 17. i.e., we must have:

$$
d\left[\left(1-\alpha_{h 2}\right) A \overline{\overline{I I}}-C_{h}\right]>d\left[\left(1-\alpha_{h 2}\right) A \overline{\overline{I I}}-C_{L}\right]
$$

So to exert a high level we must have the expected productive ability of the agent to be greater than the productivity requirement of contract 1 such that:

$\alpha_{h 2}<1-\frac{C_{h}-C_{l}}{A(\overline{\overline{I I}}-\overline{I I})}$

Now we compare (18) and (19):

Payoff in node $18=-\left(1-\beta_{1}\right) F-C_{h}+d\left[\left(1-\alpha_{h 2}\right) \overline{\overline{I I}}-C_{h}\right]$ Payoff in node $19=-\left(1-\beta_{1}\right) F-C_{h}+d\left[\left(1-\alpha_{h 2}\right) \overline{I I}-C_{l}\right]$

For payoff in (18) to be greater than that of (19) we must have:

$$
\left(1-\alpha_{h 2}\right) \overline{\overline{I I}}-\bar{\Pi}>C_{h}-C_{l}
$$

In other words:

$\alpha_{h 2}<1-\frac{C_{h}-C_{l}}{(\overline{\overline{I I}}-\overline{I I})}$

Now we compare the pair (4 and 5) and (6 and 7):

Node (4) emanates from node (12) as we have to meet the condition in Equation (3) Node (5) emanates from node (14) the payoff in node (14) is proven to be greater than that of node (15):

Payoff in node $4=-(1-\beta 1) F-C_{h}+d\left[\left(1-\alpha_{12}\right) A \overline{\overline{I I}}-C_{h}\right]$

Payoff in node $5=-\left(1-\beta_{1}\right) F-C_{l}+d\left[W_{h}-C_{h}\right]$

For the payoff in (4) to exceed that of (5) we must have:

$\alpha_{l 2}<1-\frac{1}{A \overline{I I}}\left[\frac{C_{h}-C_{l}}{d}+W_{h}\right]$ 
Now we compare node (6) and (7):

Payoff in node $6=-\left(1-\beta_{1}\right) F-C_{h}+d\left[\left(1-\alpha_{h 2}\right) A \overline{I I}-C_{h}\right]$

Payoff in node $7=-\left(1-\beta_{1}\right) F-C_{l}+d\left[\left(1-\alpha_{h 2}\right) \overline{I I}-C_{h}\right]$

For payoff in (6) to be greater than 7 we must have:

$$
\alpha_{h 2}<1-\frac{1}{\overline{I I}}\left[\frac{C_{h}-C_{l}}{d(A-1)}\right]
$$

\section{Discussion}

From the preceding results we need to develop sharing ratios for each type contract that satisfies both the agent and the financier.

\section{Contract 1: Output Only}

For the financier to at least make profit from contract 1 his sharing ratio should respect the condition in Equation (1). For the agent to fulfill his obligations and exert a high effort the sharing ratio must fulfill the condition in Equation (7):

$$
\begin{aligned}
& \frac{F\left[\beta_{1}\left(1+p_{1}\right)\left(1+\delta\left(1+p_{2}\right)\right)+\delta\left(1+p_{2}\right)\right]}{\delta \overline{\overline{I I}}} \\
& \leq \alpha_{h} 2 \leq \operatorname{Min}\left\{1-\frac{1}{\overline{\overline{I I}}}\left[\frac{C_{h}-C_{l}}{d(A-1)}\right] ; 1-\frac{C_{h}-C_{l}}{A(\overline{\overline{I I}}-\overline{I I})}\right\}
\end{aligned}
$$

\section{Contract 2: Effort Only}

For the financier to at least break even from contract 2 his sharing ratio should respect the condition in Equation (2). For the agent to fulfill his obligations and exert a high effort the sharing ratio must fulfill the condition in Equation (6):

$$
\begin{aligned}
& \frac{F\left[\beta_{1}\left(1+p_{1}\right)\left(1+\delta\left(1+p_{2}\right)\right)+\delta\left(1+p_{2}\right)\right]}{\delta A \overline{I I}} \\
& \leq \alpha_{l 2} \leq \operatorname{Min}\left\{1-\frac{1}{\overline{\overline{I I}}}\left[\frac{C_{h}-C_{l}}{d}+W_{h}\right] ; 1-\frac{C_{h}-C_{l}}{A(\overline{\overline{I I}}-\overline{I I})}\right\}
\end{aligned}
$$

The two inequalities show two facts:

The minimum sharing ratio of the effort based contract is always lower than that of the output based contract. In fact since $A>1$ and $A \overline{\overline{I I}}>\overline{I I}$ we have:

$$
\begin{aligned}
& \frac{F\left[\beta_{1}\left(1+\rho_{1}\right)\left(1+\delta\left(1+\rho_{2}\right)\right)+\delta\left(1+\rho_{2}\right)\right]}{\delta A \overline{\overline{I I}}} \\
& <\frac{F\left[\beta_{1}\left(1+\rho_{1}\right)\left(1+\delta\left(1+\rho_{2}\right)\right)+\delta\left(1+\rho_{2}\right)\right]}{\delta \bar{I}}
\end{aligned}
$$

An effort based contract offer more span for negotiation.

In fact to calculate the Span of Negotiation (SN) we take the difference between the maximum and the minimum value of the sharing ratio of each contract we have for contract 1 (the output based):

$$
\begin{aligned}
& S N_{c 1}=\operatorname{Min}\left\{1-\frac{1}{\overline{I I}}\left[\frac{C_{h}-C_{l}}{d(A-1)}\right] ; 1-\frac{C_{h}-C_{l}}{A(\overline{\overline{I I}}-\overline{I I})}\right\} \\
& -\frac{F\left[\beta_{1}\left(1+\rho_{1}\right)\left(1+\delta\left(1+\rho_{2}\right)\right)+\delta\left(1+\rho_{2}\right)\right]}{\delta \bar{I}}
\end{aligned}
$$

For contract 2 (the effort based)

$$
\begin{aligned}
& S N_{c 2}=\operatorname{Min}\left\{1-\frac{1}{\overline{\overline{I I}}}\left[\frac{C_{h}-C_{l}}{d}+W_{h}\right] ; 1-\frac{C_{h}-C_{l}}{A(\overline{\overline{I I}}-\overline{I I})}\right\} \\
& -\frac{F\left[\beta_{1}\left(1+\rho_{1}\right)\left(1+\delta\left(1+\rho_{2}\right)\right)+\delta\left(1+\rho_{2}\right)\right]}{\delta A \overline{\overline{I I}}}
\end{aligned}
$$

To prove that an effort based contract offer more span of negotiation we take the difference between the two spans and apply the limit of the difference as the productivity $A$ goes to infinity:

$$
\lim _{A \rightarrow \infty}\left[S N_{c 2}-S N_{c 1}\right]=\frac{F\left[\beta_{1}\left(1+\rho_{1}\right)\left(1+\delta\left(1+\rho_{2}\right)\right)+\delta\left(1+\rho_{2}\right)\right]}{\delta \bar{I}}>0
$$

\section{Conclusion}

In this research we dealt with a specific kind of projects that of new project. The specific case of new projects comes from the fact that they are usually characterized by difficult conditions at their initial stage but then can prosper at later stages. This poses a problem in musharakah contracts in terms of determining the adequate sharing ratio. This problem comes from the fact that the sharing ratio does not only depend on the effort to be exercised by the agent but also on the market conditions. To overcome this problem we proposed two types of contracts. One is effort based It compensates the agent for the effort provided regardless of market conditions. The other type of contract is output based where the agent compensation is based solely on output realized. Our intuition is that an agent opting for an output based signals a reliance on market condition and 
therefore a lower effort ability meriting lower compensation. The opposite is true when the agent shows confidence by choosing an effort based contract. We found theoretical evidence that an effort based contract offer better compensation to the agent in the form of lower sharing ratio to the financier. This result has two important Islamic implications. First it emphasizes the sentiment of altruism which the financier shows by taking a smaller sharing ratio. Second it emphasizes the sentiment of positive reciprocity which the agent exhibits by providing high effort. Another important finding is that an effort based contract offers more span of negotiation than an output based contract. This is an important Islamic concept as the agent has fewer restrictions in terms of negotiations. To test the validity of the model we propose an extension of this model using field and empirical study.

\section{Acknowledgment}

We would like to thank the following contributors for their valuable help in the construction of this research:

- Dr Sami Al Suwailem: Senior Economist at Islamic Development Bank, Saudi Arabia

- Dr Nabi Mahmoud Sami: Head of the Economics Department at Tunisia Polytechnic SchoolUniversity of Carthage

- Dr Mohamed Karrat: Professor of Islamic Jursprudence in Al Qarawiyyin University (Morocco), Associate partner at Al Maali Consulting (Islamic finance consulting firm, Morocco), member of the 'International Islamic Centre for Reconciliation and Arbitrage (IICRA)

- Dr Sami As Soulaimani: Associate managing director of Fineopolis consulting, Morocco (an Islamic finance consultancy firm)

\section{Funding Information}

This work is done in collaboration with the ministery of higher education in Morocco through L'Ecole Mohamadia d'ingenieur and the Islamic development bank in Jeddah. The support was achieved via the provision of the laboratory facilities.

\section{Author's Contributions}

This study is the result of the full and equal collaboration of all the authors:

Adil ELFakir: Ideas generation; literature review and model and mathematical design and equal contribution to Result validation and discussion.

Mohamed Tkiouat: Ideas genaeration, Designing the methodology, mathematical validation and equal contribution to result validation and discussion.

\section{Ethics}

This article is original and contains unpublished material. The corresponding author confirms that all of the other authors have read and approved the manuscript and no ethical issues involved.

\section{References}

Al-Suwailem, S., 2006. Hedging in Islamic Finance. 1st Edn., Islamic Development Bank, Islamic Research and Training Institute, ISBN-10: 9960321606, pp: 150.

Berger, A.N., W.S. Frame and V. Ioannidou, 2011. Tests of ex ante versus ex post theories of collateral using private and public information. J. Financ. Econom., 100: 85-97. DOI: $10.1016 /$ j.jfineco.2010.10.014

Brown, M. and C. Zehnder, 2010. The emergence of information sharing in credit markets. J. Financ. Int., 19: 255-278. DOI: 10.1016/j.jfi.2009.03.001

Djankov, S., C. McLiesh and A. Shleifer, 2007. Private credit in 129 countries. J. Financ. Econom., 84: 299-329.

DOI: $10.1016 /$ j.jfineco.2006.03.004

ELFakir, A. and M. Tkiouat, 2015. An incentive game theory approach to musharakah contracts. Asian J. Applied Sci., 3: 736-752.

Gehrig, T. and R. Stenbacka, 2007. Information sharing and lending market competition with switching costs and poaching. Eur. Econo. Rev., 51: 77-99. DOI: 10.1016/j.euroecorev.2006.01.009

Hertzberg, A., J. Liberti and D. Paravisini, 2011. Public information and coordination: Evidence from a credit registry expansion. J. Finance, 66: 379-412. DOI: $10.1111 /$ j.1540-6261.2010.01637.x

Innes, R.D., 1990. Limited liability and incentive contracting with ex-ante action choices. J. Econo. Theory, 52: 45-67. DOI: 10.1016/0022-0531(90)90066-S

Karim, A.A., 2002. Incentive-Compatible Constraints for Islamic Banking: Some Lessons from Bank Muamalat. In: Islamic Banking and Finance: New Perspectives on Profit Sharing and Risk, Iqbal, M. and D.T. Llewellyn (Eds.), Edward Elgar Publishing, Cheltenham, UK, ISBN-10: 1843765314, pp: 95-108.

Maheran, M., 2010. New musharakah model in managing Islamic investment. ISRA Int. J. Islamic Finance, 2: 25-36.

Nabi, M.S., 2013. Access to finance and investment: Does profit sharing dominate debt? Islamic Research and Training Institute.

Padilla, A.J. and M. Pagano, 1997. Endogenous communication among lenders and entrepreneurial incentives. Rev. Financial Stud., 10: 205-236.

DOI: $10.1093 / \mathrm{rfs} / 10.1 .205$ 
Pagaon, M. and T. Jappelli, 1993. Information sharing in credit markets. J. Finance, 48: 1693-1718. DOI: 10.1111/j.1540-6261.1993.tb05125.x

Rammal, H.G., 2004. Financing through musharaka: Principles and application. Business Quest.

Shaikh, S.A., 2011. A critical analysis of mudarabah and a new approach to equity financing in Islamic finance. J. Islamic Bank. Finance.

Subramanian, N., A. Chakraborty and S.A. Sheikh, 2002. Performance incentives, performance pressure and executive turnover. Social Science Electronic Publishing.
Usmani, M.I.A., 2002. Meezanbank's Guide to Islamic Banking. 1st Edn., Darul-Ishaat, Karachi, pp: 259.

Warde, I., 2010. Islamic Finance in the Global Economy. 1st Edn., Edinburgh University Press, Edinburgh, ISBN-10: 0748627774, pp: 271.

Yousfi, O., 2013. Does pls solve moral hazard problems? J. Islamic Econom. Bank. Finance, 9: 11-26. 